\title{
Sex, Power, and Women: Female Viewers' Perceptions of Popular Music Video Themes
}

\author{
Whitney Stefani and Ralf Greenwald* \\ Psychology Department, Central Washington University, Ellensburg, WA 98926-7575, United States
}

\begin{abstract}
Received: October 28, 2013; Accepted: J anuary 06, 2014; Published: J anuary 08, 2014
*Corresponding author: Ralf R Greenwald, Psychology Department, Central Washington University, Ellensburg, WA 98926-7575, United States, Tel: 509.963.3630;E-mail: greenwar@cwu.edu
\end{abstract}

\begin{abstract}
Research has linked viewing highly sexual music videos with increased gender role acceptance, and concern over personal physical appearance. However, very few studies have assessed individual differences in how music video sexual content is perceived, and no studies to date have addressed non-objectifying sexual content. In the present study, fifteen college women were exposed to 21 pop music videos and asked to categorize each video on the basis of whether it depicted women a) as sex objects, b) using sex as a source of power, or c) non-sexually. At least one video achieved perfect consensus amongst the participants for each category of sexual content, indicating that not all highly sexual portrayals of women are seen as objectifying by college women. However, the participants did not categorize the remaining videos in a uniform manner, indicating that there are considerable individual differences in the perception of music video sexual content.
\end{abstract}

Keywords: Music video; Objectification; Sexual content; Video categorization; Content analysis

\section{Introduction}

Over the past several decades, psychologists have developed a sizeable body of research detailing the music video viewing habits of teenagers and college students. Research has shown that these age groups frequently view music videos $[1,2]$. Currently, videos are widely available on the Internet, and video-hosting sites have become popular. For example, YouTube affiliate Vevo averages 1.4 billion views per month and 10 music videos per session [3]. Clearly, music videos are a popular source of entertainment for adolescents and young adults. However, there is a lack of research investigating the effects of music videos on the attitudes and wellbeing of viewers. This study aimed to assess how college women perceive the sexual content of music videos, specifically, to determine if they view some content as linking sex not with objectification, but with power. The following introduction will address some of the key issues in music video research, including the prevalence of sexual content and gender stereotypes, effects of music video viewing on gender schemas, and lastly, differentiating between types of sexual content in music videos.

\section{Identifying sexual content in music videos}

Research has shown that music video imagery has often been highly sexual $[4,5]$. Estimates of the prevalence of sexual content in music videos have ranged from 36-75\%, depending on the year, definition of "sexual content," and the type of sampling used [5]. Typical examples of sexual content identified in music video research have included provocative dress or dancing and sexual touching, such as caressing oneself or kissing [6-8]. However, the coding schemes used in music video research have typically been more adept at identifying overt than covert sexual content, such as makeup or close-ups of attractive faces.

The sexual content of music videos has tended to be gender stereotypic. Specifically, women in music videos have often been portrayed as the objects of sexual attention, for the gratification of on or off-screen men [7,9]. The supporting female characters in music videos have often appeared as hypersexual objects without agency, lack a role outside their function as living decor, or have no identifiable personality traits [9]. Unfortunately, researchers have devoted far less attention to stereotypic representations of masculinity in music videos; however, it appears that men have not been sexualized to the same extent as women [10].

\section{Effects of sexual music videos on viewers' gender schemas}

Research suggests that music videos with sexual content have an effect on viewers' attitudes towards gender roles, including gender roles in the context of a sexual relationship $[11,7,5]$. These findings are explained by two theories of cognition, namely, the Social Learning Theory and the Priming Theory. The Social Learning Theory claims that individuals learn from modeled behaviors [12]. In this view, the repetition of stereotyped depictions of men and women in the media help shape children's gender schemas, leading children to perceive masculinity and femininity in more traditional and rigid ways [13].

Priming may also play a role in how viewers perceive the sexual content of a music video. According to Priming Theory, different stimuli activate different schemas, or blueprints of a construct, which can influence cognition or behavior [14]. If audiences consider music videos to be a heavily sexualized media overall, or a particular artist to have a hypersexual persona, they may view individual videos with sex-related schemas already 
activated. Because content analyses have not typically addressed all covert sexual content or priming effects, the current statistics may underestimate the prevalence of sexual content in music videos.

Both the Social Cognitive and Priming theories suggest that media consumption influences viewer's attitudes towards men and women, and experimental evidence supports these claims. For example, watching music videos rated as highly sexual by participants has been positively correlated with endorsement of double-standards with respect to male and female sexual behavior. This effect was apparent even after factoring out the influences of other types of television viewing, gender, and personal sexual experience [5].

\section{Distinguishing between types of sexual content}

The majority of research on music videos has investigated their negative effects. However, there has been comparatively little research into the effects of sexual content type on body dissatisfaction or sex schemas. Taylor and Setters [15] found that women watching highly attractive, highly aggressive female film protagonists endorsed both more stereotypically masculine and feminine gender roles for women relative to women watching less attractive and/or less aggressive female protagonists, provided that they also perceived the character as being worthy of emulation. The authors suggest that this is due to spreading activation, whereby the priming of one component of a schema activates the other components. Thus, the schemas activated by media may pertain to how women should behave, not how women actually do behave, generating a "Superwoman ideal". In other words, the stereotypically masculine components of the participant's "ideal woman" schema do not replace the feminine components, but are additive [15].

The sexual content of music videos may fall into similar "stereotypically masculine" and "stereotypically feminine" categories, with effects comparable to those seen by Taylor and Setters. For example, [16] have argued that artists use sexual content in their music videos for different purposes. They identified three uses of sexual content: "sex as metamorphosis," "sex as fantasy fulfillment," and "sex as power" (i.e., using sex to wield power over others). These categories are not mutually exclusive [16], but do allow for more precise descriptions of sexual content than most researchers use. It is conceivable that these different types of sexual content activate different components of viewer's schemas of femininity or ideal femininity. The present study focuses on the two components most directly relevant to traditionally feminine and traditionally masculine gender roles: Sex Object and Sex as Power.

\section{Sex object music videos}

The existing literature tends to distinguish between high and low levels of sexual content, with no analysis of the specific type of sexual content. However, some content analyses have drawn contrasts between the passivity of female sexual behaviors in music videos and the activity of male behaviors generally $[17,10]$. Researchers have attempted to demonstrate the effects on viewers of these portrayals of women as "sex objects," people with sex appeal but no other prominent traits. However, it is not necessarily true that participants and researchers will perceive the music videos used in a study in the same way. For example, [18] included in their non-sexual control group videos containing suggested nudity, grinding dance moves, lyrics endorsing traditional gender roles, close-ups of female body parts, and sexual touching of a woman's body.

\section{Sex as power music videos}

The Sex as Power theme may be of particular interest to researchers, as this theme combines the gender-stereotypical focus on women's appearance with norm-violating depictions of female agency, competency, and control. Because of this apparently "mixed message" or combination of traditional and non-traditional gender roles, Sex as Power videos may have different effects from Sex Object videos. If audiences interpret Sex as Power messages as validating female status and agency in a way directly antithetical (i.e., not additive) to traditional feminine stereotypes, this type of sexual content may not have the same negative effects as traditional depictions of female sexuality. Indeed, it may have a positive effect. Alternatively, audiences may not be able to distinguish between Sex as Power videos and other videos, or the videos may contain competing messages that mitigate any positive effects, as in the [15] study. The sexualization of female power may also serve to undermine feminism and propagate sexism [19].

Psychological research has traditionally grouped all types of sexual content into a single type and correlated high levels of this content with gender stereotyping and anxieties about appearance. However, the research to date has not empirically demonstrated the effects of Sex as Power messages on music video viewers. Supporting the notion that the effect of such videos may differ from those of Sex Object videos, adolescents who listen to music with "non-degrading" sexual lyrics (as rated by researchers) are less likely to initiate sexual intercourse than those who listen to "degrading" sexual lyrics, even after controlling for other predictors of sexual activity [20]. A study that is currently in press does indicate that some college women view sexual objectification itself as empowering (S. Hust, personal communication). Perhaps this perception is dependent on the type of sexual content, with some sexual content being perceived as more empowering than others.

In order to accurately assess the effects of Sex Object versus Sex as Power content in music videos, it is necessary to determine if undergraduate women do indeed distinguish between Sex Object and Sex as Power videos. It is also necessary to identify specific music videos that fit each category and could be used in experimental research. This information is vital to evaluating claims about the damage and benefits of sexualized media to women's psychological wellbeing.

\section{The present study}

The present study investigated whether or not the proposed categories of Sex Object, Sex as Power, and Non-Sexual are valid 
with respect to undergraduate college women's perceptions of pop music videos. Additionally, the study examined the degree to which participants perceived music video sexual content in a predictable, uniform manner. These questions were investigated by providing a small group of women with a qualitative coding scheme and determining if and where statistically-significant levels of interrater agreement could be achieved in coding the sexual content of each individual video. Since previous research has shown gender differences in perception of sexual themes in video clips, only female participants were selected [21].

This study employed a receiver-oriented content analysis, in which untrained participants report how they perceive the content of a given unit. This methodology allows for greater external validity when describing how viewers are impacted content [22-23]. To increase the likelihood that the videos would vary in their sexual content, purposive sampling was employed. Specifically, videos were selected on the basis of the researchers' beliefs that they fit a given category. These preliminary categorizations are shared in Table 1. However, it is important to note that the researchers' assessments were not shared with the participants or included in the actual content analysis of the sample. That is, the researchers' preliminary assessments served only to identify a sample amenable to the content analysis that was later performed by the participants.

It was hypothesized that participants would be able to distinguish between categories of sexual content. Specifically, it was expected that individuals would rate each video as being a strong example of one category and a weak example of the others. Additionally, this study expected that a consensus would be achieved as to the categorization of at least some of the videos.

\section{Method}

\section{Participants}

A convenience sample of fifteen college undergraduate female participants were recruited through the university online recruiting system. The study description informed potential participants that they would be asked to watch pop music videos. As compensation, participants were able to enter their names in a lottery for a $\$ 100$ Amazon gift card. Participants' mean age was 20.5 years $(S D=2.42) .60 \%$ of participants identified as Caucasian $(n=9), 13 \%$ as African-American $(n=2), 6 \%$ as Hispanic $(n=1)$, and $20 \%$ as biracial or mixed $(n=3)$.

\section{Materials}

Participants used a computer to individually view randomly selected videos from a set of 21 pre-selected popular music videos that the researcher considers representative of a particular category (Sex Object, Sex as Power, or Non-Sexual) (see Table 1). To avoid fatiguing the participants, each viewed only seven of the 21 music videos.

Each video featured a female artist and/or female characters. Additionally, male main characters or artists were present in three of the seven Sex as Power videos, four of the seven Sex Object videos, and three of the Non-Sexual music videos.
Whenever possible, videos were selected that shared an artist but differed in their proposed categorization. The average number of YouTube hits for the videos was kept as consistent as possible across categories by disqualifying videos that had been seen fewer than approximately 10 million times, with "The Lady Is a Tramp's" 9,975,692 being the lowest number of views). However, some videos were older or more popular and thus had more views (i.e., "I Gotta Feeling" at over 128 million views). With the exception of The Lady is a Tramp, a jazz song featuring a pop artist, all of the songs featured was of the pop or hip-hop genres. This was chosen to avoid confounds due to genre, and because of the popularity and ubiquity of these genres.

\section{Procedures}

All procedures were approved by the university Human Subjects Review Committee. When participants finished watching each video, they were given definitions of each category. Participants then indicated which of the three categories the video belonged to. The definition of Sex Object videos stated that "The women are not powerful or in control of the situation, but instead are passive. They are weak or vulnerable. The women are shown in a highly sexual, provocative manner. In the video, the women do not use their sexuality to obtain some goal or exercise power over others. These women seem like little more than decoration-there doesn't appear to be a lot going on inside their heads".

In contrast, the definition of Sex as Power videos stated that "The women are powerful and in control of the situation. They are strong and secure. Like the sex object videos, they are shown in a highly sexual, provocative manner. The video portrays women as using their sexuality to obtain some goal or power over others. They seem like they are more than just their bodies-there is something going on inside their heads." Meanwhile, the definition of Non-Sexual videos stated that "Sexuality and sex appeal are not focused on in the video". Participants also rated the video on six subscales, reporting the extent to which they saw the video as

\begin{tabular}{|l|l|l|}
\hline Sex as Power & Sex Object & Non-Sexual \\
\hline Misery (Maroon 5) & Wake Up (Maroon 5) & $\begin{array}{l}\text { Rolling in the Deep } \\
\text { (Adele) }\end{array}$ \\
\hline $\begin{array}{l}\text { My Humps (Black-Eyed } \\
\text { Peas) }\end{array}$ & $\begin{array}{l}\text { I Gotta Feeling (Black } \\
\text { Eyed Peas) }\end{array}$ & $\begin{array}{l}\text { Where is the Love? } \\
\text { (Black Eyed Peas) }\end{array}$ \\
\hline Circus (Britney Spears) & 3 (Britney Spears) & $\begin{array}{l}\text { Already Gone (Kelly } \\
\text { Clarkson) }\end{array}$ \\
\hline $\begin{array}{l}\text { Did It On 'Em (Nicki } \\
\text { Minaj) }\end{array}$ & $\begin{array}{l}\text { Bottoms Up (Trey } \\
\text { Songz, feat. Nicki } \\
\text { Minaj) }\end{array}$ & $\begin{array}{l}\text { What the Water Gave } \\
\text { Me (Florence + the } \\
\text { Machine) }\end{array}$ \\
\hline LoveGame (Lady GaGa & You and I (Lady GaGa) & $\begin{array}{l}\text { The Lady is a Tramp } \\
\text { (Tony Bennett feat. } \\
\text { Lady GaGa) }\end{array}$ \\
\hline S\&M (Rihanna) & Umbrella (Rihanna) & $\begin{array}{l}\text { Feel it in My Bones } \\
\text { (Tiesto feat. Tegan and } \\
\text { Sara) }\end{array}$ \\
\hline $\begin{array}{l}\text { With Love (Hilary } \\
\text { Duff) }\end{array}$ & $\begin{array}{l}\text { Reach Out (Hilary } \\
\text { Duff) }\end{array}$ & $\begin{array}{l}\text { Come Clean (Hilary } \\
\text { Duff) }\end{array}$ \\
\hline
\end{tabular}

Table 1: Researcher's preliminary categorizations of videos as either sex object, sex as power, or non-sexual. 
a Sex Object, Sex as Power and Non-Sexual video, as well as the extent to which women in the video were portrayed as weak and passive, strong and active. Finally, they were asked to rate the overall intensity of the sexual content.

\section{Results}

\section{Video familiarity and appeal}

Each video had been previously seen by the participants on average 2.9 times $(S D=5.3)$, with a range of $0-100$. On a 4-point scale where 1 indicated that the participant did not like the video and 4 indicated that they liked the video very much, the average video appeal score was $2.39(S D=.59)$ (See Table 2 ).

\section{Statistical analysis}

Since more than two judges were used to rate different sets of videos, a Fleiss's Kappa was performed to assess rater agreement. Fleiss's Kappa is intended for nominal data, and a portion of the data collected in this study was ordinal. However, a weighted kappa was not appropriate for this study, as it is possible that there was a greater perceived distance between the two halves of the forced-choice Likert subscale than between the two gradations on either end. Thus, the Likert subscales were artificially dichotomized, with responses of 1 and 2 grouped as "low" and 3 and 4 grouped as "high" with respect to the trait named in the item [24-25], for examples of artificially dichotomized ordinal scales in previous research). [26] table of $k$ values was used to interpret $k$, with the caveat that the low number of categories ( 3 for the overall categorizations, 2 for the dichotomized Likert subscales) leads to inflated $k$ values. Therefore, only the most conservative cut-off value (.81, or "almost perfect agreement") was used to define consensus.

\section{Nominal categorizations}

"Already Gone," “Come Clean," "Feel It In My Bones," "What the Water Gave Me," and "Where is the Love" were unanimously coded as non-sexual. "Bottoms Up" was unanimously coded as sex object. "Misery" was unanimously coded as sex-as-power. The remaining videos did not yield consensus, except for $S \& M$, which was omitted from analysis on this variable due to missing data. Participants disagreed as to whether 5 of the 20 coded videos were sexual or non-sexual, and disagreed as to whether 10 of the videos were sex object or Sex as Power (see Table 3).

\section{Sex object subscale}

Participants unanimously rated "Bottoms Up" high on the forced-choice Sex Object subscale. Participants unanimously rated "Already Gone," "Come Clean," "Feel It In My Bones," "Misery," "Rolling in the Deep," "What the Water Gave Me," and "Where is the Love" low on the subscale. Non-significant kappas were reported for the remaining videos (see Table 4).

\section{Sex as power subscale}

Participants unanimously rated "Misery," "My Humps" and "S\&M" high on the forced-choice Sex as Power subscale. Participants unanimously rated "Already Gone," "Bottoms Up," "What the Water Gave Me," and "Where is the Love" low on the

\begin{tabular}{|c|c|c|}
\hline Video & Number of times previously seen & Appeal \\
\hline Already Gone & 0.6 & 3.0 \\
\hline Bottoms Up & 1.0 & 2.0 \\
\hline Circus & 0.5 & 2.6 \\
\hline Come Clean & 3.6 & 2.8 \\
\hline Did It On Em & 12.5 & 1.6 \\
\hline Feel It In My Bones & 0.0 & 2.2 \\
\hline I Gotta Feeling & 0.6 & 2.4 \\
\hline The Lady Is a Tramp & 0.2 & 2.2 \\
\hline LoveGame & 4.4 & 2.2 \\
\hline Misery & 0.0 & 3.0 \\
\hline My Humps & 0.0 & 2.2 \\
\hline Reach Out & 0.0 & 1.8 \\
\hline Rolling in the Deep & 2.2 & 3.0 \\
\hline S\&M & 0.8 & 1.4 \\
\hline Umbrella & 7.4 & 3.0 \\
\hline Wake Up Call & 0.0 & 2.8 \\
\hline $\begin{array}{l}\text { What the Water Gave } \\
\qquad \mathrm{Me}\end{array}$ & 0.0 & 2.4 \\
\hline Where Is the Love & 21.8 & 3.8 \\
\hline With Love & 0.4 & 2.2 \\
\hline You \& I & 0.4 & 2.0 \\
\hline 3 & 0.4 & 1.6 \\
\hline
\end{tabular}

Table 2: Video familiarity and appeal.

\begin{tabular}{|c|c|c|}
\hline Video & Most common categorization & Fleiss's kappa \\
\hline Already Gone & Non-sexual & $1.0^{*}$ \\
\hline Bottoms Up & Sex Object & $1.0^{*}$ \\
\hline Circus & Sex as Power & 0.3 \\
\hline Come Clean & Non-sexual & $1.0^{*}$ \\
\hline Did It On Em & Sex as Power & 0.4 \\
\hline Feel It In My Bones & Non-sexual & $1.0^{*}$ \\
\hline I Gotta Feeling & Sex object & 0.4 \\
\hline The Lady Is a Tramp & Non-sexual & 0.3 \\
\hline LoveGame & Sex as Power & 0.4 \\
\hline Misery & Sex as Power & $1.0^{*}$ \\
\hline My Humps & Sex as Power & 0.6 \\
\hline Reach Out & Sex Object & 0.4 \\
\hline $\mathrm{S} \& \mathrm{M}^{* *}$ & ----- & ----- \\
\hline Umbrella & Sex as Power & 0.3 \\
\hline Wake Up Call & Sex Object & 0.6 \\
\hline $\begin{array}{l}\text { What the Water Gave } \\
\qquad \mathrm{Me}\end{array}$ & Non-sexual & $1.0^{*}$ \\
\hline Where Is the Love & Non-sexual & $1.0^{*}$ \\
\hline With Love & Sex as Power & 0.6 \\
\hline You \& I & Sex Object & 0.6 \\
\hline 3 & Sex Object & 0.4 \\
\hline
\end{tabular}

* = significant values

** = omitted due to missing data

Table 3: Nominal categorizations of videos and interrater reliability statistics. 
subscale. Non-significant kappas were reported for the remaining videos (see Table 5).

\section{Non-sexual subscale}

Participants unanimously rated "Already Gone," "Come Clean," "Feel It In My Bones," "Rolling in the Deep," "What the Water Gave Me," and "Where is the Love" high on the forcedchoice Non-Sexual subscale. Participants unanimously rated "Bottoms Up," "Misery," "Reach Out," "S\&M," "You and I," and "3" low on the subscale. Non-significant kappas were reported for the remaining videos (see Table 6).

\section{Weak/passive subscale}

No videos were consistently rated high on the forced-choice Weak and Passive subscale. Participants unanimously rated "Circus," "Did It On Em," "The Lady is a Tramp," "LoveGame," "Misery," "My Humps," "S\&M," "Umbrella," "With Love" and "3" low on the subscale. Non-significant kappas were reported for the remaining videos (see Table 7).

\section{Strong/active subscale}

Participants unanimously rated "Circus," "Did It On Em," "The Lady is a Tramp," "Misery," "My Humps," "S\&M," “Umbrella," "With Love," and " 3 " high on the forced-choice Strong and Active subscale. Participants unanimously rated "Bottoms Up" and "Wake Up Call" low on the scale. Non-significant kappas were reported for the remaining videos (see Table 8).

\section{Sexual intensity subscale}

Participants unanimously rated "Bottoms Up," "LoveGame,"

\begin{tabular}{|c|c|c|c|}
\hline Video & $\begin{array}{l}\text { Most common } \\
\text { grouping }\end{array}$ & Fleiss's kappa & Mean rating \\
\hline Already Gone & Low & $1.0^{*}$ & 1.0 \\
\hline Bottoms Up & High & $1.0^{*}$ & 3.8 \\
\hline Circus & Low & 0.4 & 2.4 \\
\hline Come Clean & Low & $1.0^{*}$ & 1.4 \\
\hline Did It On Em & Low & 0.5 & 1.8 \\
\hline Feel It In My Bones & Low & $1.0^{*}$ & 1.0 \\
\hline I Gotta Feeling & High & 0.5 & 3.2 \\
\hline The Lady Is a Tramp & Low & 0.4 & 1.8 \\
\hline LoveGame & High & 0.4 & 3.0 \\
\hline Misery & Low & $1.0^{*}$ & 1.6 \\
\hline My Humps & High & 0.4 & 2.8 \\
\hline Reach Out & High & 0.4 & 3.2 \\
\hline Rolling in the Deep & Low & $1.0^{*}$ & 1.0 \\
\hline S\&M & High & 0.4 & 2.6 \\
\hline Umbrella & Low & 0.5 & 2.0 \\
\hline Wake Up Call & High & 0.4 & 3.2 \\
\hline $\begin{array}{c}\text { What the Water } \\
\text { Gave Me }\end{array}$ & Low & $1.0^{*}$ & 1.0 \\
\hline Where Is the Love & Low & $1.0^{*}$ & 1.0 \\
\hline With Love & Low & 0.4 & 2.0 \\
\hline You \& I & High & 0.5 & 3.0 \\
\hline 3 & High & 0.4 & 3.2 \\
\hline
\end{tabular}

Table 4: Sex object subscale and interrater agreement statistics.

\begin{tabular}{|c|c|c|c|}
\hline Video & $\begin{array}{l}\text { Most common } \\
\text { grouping }\end{array}$ & Fleiss's kappa & Mean rating \\
\hline Already Gone & Low & $1.0^{*}$ & 1.0 \\
\hline Bottoms Up & Low & $1.0^{*}$ & 1.4 \\
\hline Circus & High & 0.4 & 2.8 \\
\hline Come Clean & Low & 0.5 & 1.6 \\
\hline Did It On Em & High & 0.4 & 2.6 \\
\hline Feel It In My Bones & Low & 0.4 & 1.8 \\
\hline I Gotta Feeling & High & 0.4 & 2.6 \\
\hline The Lady Is a Tramp & Low & 0.5 & 2.0 \\
\hline LoveGame & High & 0.5 & 3.2 \\
\hline Misery & High & $1.0^{*}$ & 4.0 \\
\hline My Humps & High & $1.0^{*}$ & 3.6 \\
\hline Reach Out & High & 0.4 & 2.8 \\
\hline Rolling in the Deep & Low & 0.5 & 1.6 \\
\hline S\&M & High & $1.0^{*}$ & 3.8 \\
\hline Umbrella & High & 0.5 & 2.8 \\
\hline Wake Up Call & Low & 0.5 & 1.8 \\
\hline $\begin{array}{l}\text { What the Water Gave } \\
\text { Me }\end{array}$ & Low & $1.0^{*}$ & 1.2 \\
\hline Where Is the Love & High & 0.5 & 3.0 \\
\hline With Love & Low & 0.4 & 2.0 \\
\hline You \& I & Low & 0.4 & 2.4 \\
\hline 3 & High & 0.5 & 2.8 \\
\hline
\end{tabular}

* = significant values

Table 5: Sex as power subscale and interrater agreement statistics.

\begin{tabular}{|c|c|c|c|}
\hline Video & $\begin{array}{l}\text { Most common } \\
\text { grouping }\end{array}$ & Fleiss's kappa & Mean rating \\
\hline Already Gone & High & $1.0^{*}$ & 4.0 \\
\hline Bottoms Up & Low & $1.0^{*}$ & 1.0 \\
\hline Circus & Low & 0.4 & 2.2 \\
\hline Come Clean & High & $1.0^{*}$ & 4.0 \\
\hline Did It On Em & High & 0.4 & 2.6 \\
\hline Feel It In My Bones & High & $1.0^{*}$ & 3.8 \\
\hline I Gotta Feeling & Low & 0.5 & 1.6 \\
\hline The Lady Is a Tramp & High & 0.5 & 3.6 \\
\hline LoveGame & Low & 0.4 & 2.2 \\
\hline Misery & Low & $1.0^{*}$ & 1.0 \\
\hline My Humps & Low & 0.5 & 1.6 \\
\hline Reach Out & Low & $1.0^{*}$ & 1.2 \\
\hline Rolling in the Deep & High & $1.0^{*}$ & 3.8 \\
\hline S\&M & Low & $1.0^{*}$ & 1.0 \\
\hline Umbrella & Low & 0.5 & 2.8 \\
\hline Wake Up Call & Low & 0.5 & 1.6 \\
\hline $\begin{array}{c}\text { What the Water Gave } \\
\text { Me }\end{array}$ & High & $1.0^{*}$ & 3.8 \\
\hline Where Is the Love & High & $1.0^{*}$ & 4.0 \\
\hline With Love & Low & 0.4 & 2.0 \\
\hline You \& I & Low & $1.0^{*}$ & 1.0 \\
\hline 3 & Low & $1.0^{*}$ & 1.2 \\
\hline
\end{tabular}

Table 6: Non-sexual scale and interrater agreement statistics. 
"My Humps," "S\&M," and "You and I" high on the forced-choice Highly Sexual subscale. Participants unanimously reported that "Already Gone," "Come Clean," "Feel It In My Bones," "The Lady is a Tramp," "Rolling in the Deep," "What the Water Gave Me," and "Where is the Love" low on the scale. Non-significant kappas were reported for the remaining videos (see Table 9).

\section{Discussion}

This study sought to assess via interrater agreement statistics whether college women distinguish between Sex Object, Sex as Power, and Non-Sexual music videos, and to identify music videos that college women perceive as exemplifying these categories. Participants' nominal categorizations of the sexual content varied widely for some videos, and were unanimous for others. The implications of these finding are threefold: (a) college women differentiate between types of sexual content, namely Sex Object and Sex as Power, (b) researchers should not assume that viewers perceive sexual content in a way consistent with the researchers or with each other, and (c) nonetheless, some videos are sufficiently unambiguous in their sexual content type to elicit consensus amongst viewers. Thus, these videos can be used as experimental manipulations in further research.

Participants identified five videos as being non-sexual ("Already Gone," "Come Clean," "Feel It In My Bones," "What the Water Gave Me," and "Where Is the Love"), one as being sex

\begin{tabular}{|c|c|c|c|}
\hline Video & $\begin{array}{l}\text { Most common } \\
\text { grouping }\end{array}$ & Fleiss's kappa & Mean rating \\
\hline Already Gone & Low & 0.5 & 1.8 \\
\hline Bottoms Up & High & 0.5 & 3.4 \\
\hline Circus & Low & $1.0^{*}$ & 1.0 \\
\hline Come Clean & Low & 0.5 & 2.0 \\
\hline Did It On Em & Low & $1.0^{*}$ & 1.2 \\
\hline Feel It In My Bones & Low & 0.4 & 2.4 \\
\hline I Gotta Feeling & High & 0.4 & 2.2 \\
\hline The Lady Is a Tramp & Low & $1.0^{*}$ & 1.0 \\
\hline LoveGame & Low & $1.0^{*}$ & 1.2 \\
\hline Misery & Low & $1.0^{*}$ & 1.0 \\
\hline My Humps & Low & $1.0^{*}$ & 1.2 \\
\hline Reach Out & Low & 0.4 & 2.2 \\
\hline Rolling in the Deep & High & 0.6 & 1.6 \\
\hline S\&M & Low & $1.0^{*}$ & 1.4 \\
\hline Umbrella & Low & $1.0^{*}$ & 1.4 \\
\hline Wake Up Call & Low & 0.4 & 2.4 \\
\hline $\begin{array}{c}\text { What the Water Gave } \\
\text { Me }\end{array}$ & Low & 0.4 & 2.0 \\
\hline Where Is the Love & Low & 0.5 & 1.4 \\
\hline With Love & Low & 1.0 & 1.4 \\
\hline You \& I & Low & 0.4 & 2.4 \\
\hline 3 & Low & 1.0 & 1.4 \\
\hline
\end{tabular}

Table 7: Weak/passive subscale and interrater agreement statistics.

\begin{tabular}{|c|c|c|c|}
\hline Video & $\begin{array}{l}\text { Most common } \\
\text { grouping }\end{array}$ & Fleiss's kappa & Mean rating \\
\hline Already Gone & Low & 0.4 & 2.4 \\
\hline Bottoms Up & Low & $1.0^{*}$ & 1.2 \\
\hline Circus & High & $1.0^{*}$ & 3.6 \\
\hline Come Clean & High & 0.5 & 3.0 \\
\hline Did It On Em & High & $1.0^{*}$ & 3.6 \\
\hline Feel It In My Bones & Low & 0.4 & 2.0 \\
\hline I Gotta Feeling & Low & 0.4 & 2.8 \\
\hline The Lady Is a Tramp & High & $1.0^{*}$ & 3.6 \\
\hline LoveGame & High & 0.5 & 3.0 \\
\hline Misery & High & $1.0^{*}$ & 4.0 \\
\hline My Humps & High & $1.0^{*}$ & 3.8 \\
\hline Reach Out & Low & 0.4 & 2.4 \\
\hline Rolling in the Deep & High & 0.5 & 3.2 \\
\hline S\&M & High & $1.0^{*}$ & 3.4 \\
\hline Umbrella & High & $1.0^{*}$ & 3.4 \\
\hline Wake Up Call & Low & $1.0^{*}$ & 1.6 \\
\hline $\begin{array}{l}\text { What the Water Gave } \\
\qquad \mathrm{Me}\end{array}$ & Low & 0.4 & 2.6 \\
\hline Where Is the Love & High & 0.5 & 3.4 \\
\hline With Love & Low & $1.0^{*}$ & 3.4 \\
\hline You \& I & Low & 0.5 & 2.6 \\
\hline 3 & High & $1.0^{*}$ & 3.6 \\
\hline
\end{tabular}

* = significant values

Table 8: Strong/active subscale and interrater agreement statistics.

\begin{tabular}{|c|c|c|c|}
\hline Video & $\begin{array}{l}\text { Most common } \\
\text { grouping }\end{array}$ & Fleiss's kappa & Mean rating \\
\hline Already Gone & Low & $1.0^{*}$ & 1.0 \\
\hline Bottoms Up & High & $1.0^{*}$ & 3.2 \\
\hline Circus & Low & 0.4 & 2.4 \\
\hline Come Clean & Low & $1.0^{*}$ & 1.0 \\
\hline Did It On Em & Low & 0.4 & 2.2 \\
\hline Feel It In My Bones & Low & $1.0^{*}$ & 1.2 \\
\hline I Gotta Feeling & Low & 0.5 & 2.8 \\
\hline The Lady Is a Tramp & Low & $1.0^{*}$ & 1.4 \\
\hline LoveGame & High & $1.0^{*}$ & 3.0 \\
\hline Misery & High & 0.5 & 3.6 \\
\hline My Humps & High & 0.5 & 3.2 \\
\hline Reach Out & High & 0.5 & 3.2 \\
\hline Rolling in the Deep & Low & $1.0^{*}$ & 1.0 \\
\hline$S \& M$ & High & $1.0^{*}$ & 4.0 \\
\hline Umbrella & Low & 0.4 & 2.4 \\
\hline Wake Up Call & High & 0.4 & 3.0 \\
\hline What the Water Gave Me & Low & $1.0^{*}$ & 1.0 \\
\hline Where Is the Love & Low & $1.0^{*}$ & 1.0 \\
\hline With Love & Low & 0.4 & 0.4 \\
\hline You \& I & High & $1.0^{*}$ & 3.8 \\
\hline 3 & High & 0.4 & 3.2 \\
\hline
\end{tabular}

$*$ significant value

Table 9: Highly sexual subscale and interrater agreement statistics. 
object ("Bottoms Up"), and one as being sex-as-power ("Misery"). The remaining eleven videos did not yield a strong consensus. The majority of disagreements occurred between the latter two categories. Apparently, the distinction between Non-Sexual and sexual videos is less ambiguous than the distinction between Sex as Power and Sex Object.

Both of these patterns suggest that sexual or non-sexual videos are defined largely by relatively overt characteristics (i.e., kissing, provocative dancing), whereas distinctions between the messages contained in sexual content are more subtle or subjective. Thus, variables that are sexual in nature and yield high interrater agreements may be useful in determining whether a video is sexual or non-sexual. However, when making distinctions between Sex Object and Sex as Power videos, participants may need to rely in part on their less reliable perceptions of men and women's "checking out" gazes and decorative role in addition to the more overt elements, thereby reducing consensus.

Interestingly, one video lacking overt sexual content ("Rolling in the Deep") was perceived by some participants as being Sex as Power. Other videos with ostensibly overt sexual content were perceived by others as being Non-Sexual (i.e., "Circus"). Several factors may account for these discrepancies: inattention on behalf of the viewer, outside information that contributes to the schema the viewer applies to the video (e.g., perceiving a video as non-sexual because it is less sexual than other videos the artist has produced), individual differences in what types of physical characteristics and behaviors are perceived as sexual, and greater or lesser sensitivity to cues of sexual content. For example, it is possible that viewers who believe that Adele exhibits confidence in her plus-size figure and conservative wardrobe may perceive her appearance as being in defiance of celebrity norms. If they also perceive Adele as attractive, this mix of attractiveness and defiance in look and dress may combine to create a message of Sex as Power.

Based on the results of this study, it is not yet clear what constitutes a Sex as Power versus a Sex Object video in the minds of college women. However, there are clear differences between the women in the Sex Object video "Bottoms Up" and the Sex as Power video "Misery." With the exception of guest rapper Nicki Minaj, the women in "Bottoms Up" are stereotypical backup dancers, often shown dancing in silhouette and in bondage. They are essentially on display, not interacting with their environment or each other but simply waiting to be touched and stared at by the singer. The singer, meanwhile, is the video's only male character and is the only character to approach others or move around in the environment. Furthermore, the lyrics seem to suggest sexual objectification, with lines like "Callin' all the girls, do you hear me?" and "Girl you know I love the way you shakin' in 'em jeans." These aspects of the video are consistent with the definition of Sex Object videos given to participants, which stated that "the women do not use their sexuality to obtain some goal or exercise power over others. These women seem like little more than decoration...".

The passivity and decorative nature of the women in "Bottoms Up" is in contrast to "Misery," where the female character is shown aggressively beating and threatening her helpless boyfriend. She is in control of the situation, with her own goals and desires that differ from her male counterpart's. Furthermore, she acts on her own sexual impulses (e.g., touching and kissing her boyfriend), rather than allowing the male character to initiate all such behaviors. Similarly, the repeated lyric "Girl, you really got me bad" suggests control over the narrator. These behaviors are all consistent with definition of Sex as Power that participants received, which stated that women in Sex as Power videos " are powerful and in control of the situation... using their sexuality to obtain some goal or power over others." Thus, it is not surprising that participants categorized the video as Sex as Power.

However, the majority of the videos in the study were not so precisely and unanimously categorized as "Bottoms Up" and "Misery." In fact, some participants coded the same videos differently when using the Likert scale as opposed to the nominal ratings. For example, raters unanimously agreed with the statement that "My Humps" was a Sex as Power video, but one participant rated it as Sex Object when using the nominal rating system. This discrepancy may be due to an overlap between the categories. In the case of "My Humps," most raters also agreed with the statement that "['My Humps'] is a sex object video." Thus, the video was seen as being representative of both. While four of the five raters agreed that the sum total message was of sex-as-power, one participant did not-perhaps this participant identified the video's sexual content cues similarly to the others, but weighed the sexually objectifying aspects more heavily than they did.

Breaking down the "My Humps" ratings further, we see that the video was unanimously rated as being highly sexual, even though one participant also rated the video as being a strong example of a Non-Sexual video. These apparently contradictory ratings may indicate a lack of reliability in the rating system. However, a similar contradictory finding was evident in the Weak and Passive / Strong and Active scales and the overall nominal rating. Participants unanimously agreed that the women in "My Humps" were strong and active, and unanimously disagreed that they were weak and passive. The Likert ratings were, in 4 out of 5 cases, at the extreme end for their respective scales. Because the definition of Sex as Power stresses female agency and the definition of Sex Object does not, the expectation was that the participants' unanimous perceptions of the women in "My Humps" as being strong and active, coupled with the unanimous perception that the video was highly sexual, would result in a rating of Sex as Power for all participants. Nonetheless, when asked to pick which category best fit the video one participant selected Sex Object. This participant had identified "My Humps" as having the components of a Sex as Power video, but the overall feel or appearance of a sex object video.

These findings suggest that perceptions of sexual content are highly complex, perhaps more so than would be expected from the relatively high inter rater agreement statistics seen in content analyses of sexual media that do not identify Sex as Power themes [27-30]. For instance, a video such as "My Humps" can be rated by the same individual as being an example of both 
categories, although the definitions were designed to be mutually exclusive. In fact, each sentence in the definition for Sex Object was the opposite of the corresponding sentence in the Sex as Power definition (i.e., "the women are not powerful or in control of the situation" versus "The women are powerful and in control of the situation"), with the exception of the shared statement that the videos were sexual in nature. One interesting question that results from these findings is, what causes viewers to apply two literally opposite definitions to the same video?

The contradictory perceptions of sexual content, and the complete lack of any videos reliably rated high on the Weak and Passive scale may result from the application of multiple schemas to the same stimulus. Researchers have typically presumed that music videos in which female characters emphasize their sex appeal are sexually objectified and subordinate to male characters $[29,10]$. However, this interpretation ignores the potential that female artists have to use their sexuality subversively, as a means of non-gender stereotypic control [31]. Sex as Power videos seem to place the burden of the representation of female sexuality into female hands, thus allowing women to use sex appeal to signify strength and status rather than gender-stereotypic weakness. For example, the lyrics of "My Humps" detail the power that the singer has over men via her sex appeal, the material gains that her sex appeal provides her, and her ability to defend herself physically from such attention. The video illustrates these claims, showing the singer confidentially posed and displaying the clothes and jewelry that male admirers have given her. Clearly, sex is linked with power and status in this video.

At the same time, "My Humps" treats the singer's sex appeal like a prized object, rather than portraying her sexuality on a more personal or holistic level. In this way, the singer and female backup dancers are shown very much like the backup dancers in sex object video "Bottoms Up." They display their bodies for men, are extremely focused on their looks, dress and dance provocatively, and are dependent on men's perceptions of their appearance for their power. In contrast to "My Humps," the Sex as Power video "Misery" featured very little overlap of categories, with the video being unanimously identified as high on Sex as Power and Strong and Active subscales and low on Sex Object, Non-Sexual, and Weak and Passive subscales (one participant did identify the video as being low both on the Highly Sexual and Non-Sexual subscales). Meanwhile, videos high on the Sex Object and/or Sex as Power subscales both featured male and female lead vocalists. Thus, the gender of the lead vocalist in a sexual video does not entirely determine how the content will be perceived. Nor does this perception appear to be fully tied to the persona of the singer, as several artists had videos ranking high and low on the same scale (i.e., Lady GaGa, The Black Eyed Peas, Hilary Duff, and Maroon 5).

Thus, it appears that some interrater disagreements arise from differences in perception of sexual content (e.g., widely-varying responses to the Weak and Passive subscale for ("LoveGame"), and others from the difficulty of reconciling two discordant themes under a single label (as described in "My Humps"). The latter circumstance may prove especially interesting to researchers. If a viewer perceives a video as having contradicting themes, what is the behavioral outcome? As discussed earlier, Sex Object videos would increase women's endorsement of gender double-standards [5] and appearance anxiety [32]. However, videos featuring women attempting to use their sexuality in an empowering fashion violate traditional gender roles [31] and could theoretically have the opposite priming effect as genderstereotypic Sex Object videos.

On the other hand, since Sex as Power videos nonetheless link sex appeal with control and status, it is conceivable that they would increase female viewers' appearance anxiety, possibly to a greater degree than would sex object videos, which do not positively link sex with these benefits. Such an effect would be similar to earlier findings that attractive, aggressive female movie characters increase the number of gender roles that female viewers apply to women, which may lead to a greater drive for thinness [15]. It seems reasonable to assert that mixedmessage videos increase or decrease either of these variables in proportion to the intensity of the messages. Alternatively, it is possible that one message might consistently be dominant over the other in terms of behavioral effects. It is also important to note that Sex as Power videos may model anti-social or risky behaviors, such as is displayed by the abusive female character in "Misery."

\section{Implications and recommendations}

The ambiguity of viewers' perception of the sexual content of some videos does not preclude the utility of these videos in future research. Indeed, studies using such videos may have greater external validity, as participants disagreed in their perceptions of the majority of the videos. As discussed, previous research has assumed that participants perceive sexual content as either Non-Sexual or Sex Object [10,5]. Additionally, the fact that only 11 out of 21 music videos in the present study were unanimously perceived as having a certain type (or lack) of such content suggests that individual differences in researchers' and participants' perception may contribute to a substantial amount of "noise." By focusing on the effects of perceived rather than assumed messages, researchers may be able to elicit larger group differences and thus uncover formerly invisible effects.

The findings of the present study have direct implications for the interpretation of music video research, and indeed media studies of sexual content generally. Studies attributing the effects of music video viewing on women to sexual objectification, without assessing participants' perceptions of the videos, may in fact be revealing an effect of presenting attractive images of women, Sex as Power themes, or sexual content in general. Without accounting for the diversity of possible perceptions of sexual content, it is impossible to determine which aspects of the videos are priming which of the viewers' schemas.

Further, the emphasis in past research on sexual objectification as opposed to other types of sexual content arguably has biased researchers away from exploring possible positive consequences of music video viewing, such as increased acceptance of female sexual expression. Future research 
addressing the role of perception as a mediator of content could provide cleaner links between video messages and their effects. Individual interpretations of video sexual content may act as protective or risk factors with respect to the negative outcomes of video viewing. Additionally, studies comparing the effects of individually perceived versus generally agreed-upon messages in a particular video would further illuminate the relationship between priming, schemas and viewing outcomes. It should also be noted that as the present study relied on participants' perceptions of the video on a holistic level, future research is required to determine the relative weights of or interactions between lyrics and imagery when categorizing content.

Finally, the present study focused on undergraduate women from a mid-sized university in a rural area. Thus, future research is necessary to assess how men and individuals of a range of age groups and cultural backgrounds perceive music video sexual content. Furthermore, participants in the present study were not trained in music video content analysis beyond the provided category definitions, in order to maximize external validity. However, future research on music video effects using participants trained in rating music video sexual content would help to assess the impact, if any, of media literacy on these outcomes.

\section{Acknowledgements}

This study received funding from the Central Washington University Graduate Student Funding Grant.

\section{References}

1. Jones S (1988) Cohesive but not coherent: Music videos, narrative and culture. Popular Music and Society 12(4): 15-29.

2. Turner J (2005) An examination of sexual content in music videos. Doctoral dissertation, University of Delaware, Newark, DE.

3. Ehrlich B (2010) Vevo ranks number one among music video viewers. Mashable.

4. Cummins R (2007) Selling music with sex: The content and effects of sex in music videos on viewer enjoyment. Journal of Promotion Management 13(1-2): 95-109.

5. Zhang Y, Miller L , Harrison K (2008) The relationship between exposure to sexual music videos and young adults' sexual attitudes. Journal of Broadcasting \& Electronic Media 52(3): 368-386.

6. Baxter RL, de Riemer C, Landini A, Leslie L, Singletary MW(1985) A content analysis of music videos. Journal of Broadcasting \& Electronic Media 29(3): 333-340.

7. Kistler M, Lee M (2010) Does exposure to sexual hip-hop music videos influence the sexual attitudes of college students? Mass Communication \& Society 13(1): 67-86.

8. Wright P (2009) Sexual socialization messages in mainstream entertainment mass media: A review and synthesis. Sexuality \& Culture: An Interdisciplinary Quarterly 13(4): 181-200.

9. Arnett J (2002) The sounds of sex: Sex in teens' music and music videos. In JD Brown, JR Steele, KW Childers (Eds.) Sexual teens, sexual media: Investigating media's influence on adolescent sexuality. Routledge, UK, pp. 253-264.

10.Wallis C (2011) Performing gender: A content analysis of gender display in music videos. Sex Roles 64(3-4):160-172.

11. Kalof L (1999) The effects of gender and music video imagery on sexual attitudes. The Journal of Social Psychology 139(3): 378-385.

12. Bandura A (1977) Social learning theory. Englewood Cliffs, PrenticeHall, New Jersy.

13. Bussey K, Bandura A (1999) Social cognitive theory of gender development and differentiation. Psychol Rev 106(4): 676-713.

14.Pichon I, Boccato G, Saroglou V (2007) Nonconscious influences of religion on prosociality: A priming study. European Journal of Social Psychology 37: 1032-1045.

15. Taylor L, Setters T (2011) Watching aggressive, attractive, female protagonists shapes gender roles for women among male and female undergraduate viewers. Sex Roles 65(1-2): 35-46.

16. Andsager J, Roe K (2003) 'What's your definition of dirty, baby?': Sex in music video. Sexuality \& Culture: An Interdisciplinary Quarterly $7(3): 79-97$

17. Sommers-Flanagan R, Sommers-Flanagan J, Davis B(1993) What's happening on music television? A gender role content analysis. Sex Roles 28 (11-12): 745-753.

18. Ward L M, Hansbrough E, Walker E (2005) Contributions of music video exposure to black adolescents' gender and sexual schemas. Journal of Adolescent Research 20(2) : 143-166.

19. Jhally S (Producer \& Director) (2007) Dreamworlds 3: Desire, sex \& power in music video. Media Education Foundation, United States.

20. Martino SC, Collins RL, Elliot MN, Strachman A, Kanouse DE, et al. (2006) Exposure to degrading versus nondegrading music lyrics and sexual behavior among youth. Pediatrics 118(2) : 430-441.

21. Manganello J A, Henderson VR, Jordan A, Trentacoste N, Martin S, et al. (2010) Adolescent judgment of Sexual content on television: Implications for future content analysis research. J Sex Res 47(4): 364-373.

22. Austin E, Pinkleton BE, Hust ST, Miller A (2007) The locus of message meaning: Differences between trained coders and untrained message recipients in the analysis of alcoholic beverage advertising. Communication Methods \& Measures 1(2): 91-111.

23. Austin E , Pinkleton B, Fujioka Y (1999) Assessing prosocial message effectiveness: Effects of message quality, production quality, and persuasiveness. J of Health Commun 4(3): 195-210.

24. Sapra M, Vahia IV, Reyes PN, Ramirez P, Cohen CI (2008) Subjective reasons for adherence to psychotropic medication and associated factors among older adults with schizophrenia. Schizophrenia Research 106(2-3): 348-355.

25. Davies RA, Maher CG, Hancock MJ (2008) A systematic review of paracetamol for non-specific low back pain. Eur Spine J 17(11): 14231430.

26. Landis JR, Koch GG (1977) The measurement of observer agreement for categorical data. Biometrics 33(1): 159-174.

27. Aubrey J, Frisby C M (2011) Sexual objectification in music videos: A content analysis comparing gender and genre. Mass Communication \& Society 14(4): 475-501

28. Frisby CM, Aubrey J (2012) Race and genre in the use of sexual objectification in female artists' music videos. Howard Journal of Communications 23(1): 66-87.

29. Gow J (1996) Reconsidering gender roles on MTV: Depictions in 
the most popular music videos of the early 1990s. Communication Reports 9(2): 151-161.

30. Zhang Y, Dixon T, Conrad K (2010) Female body image as a function of themes in rap music videos: A content analysis. Sex Roles 62(11-12): 787-797.
31. Balaji M (2010) Vixen resistin': redefining black womanhood in hiphop music videos. J Black Stud 41(1): 5-20.

32. Tiggemann M, Slater A (2004) Thin ideals in music television: A source of social comparison and body dissatisfaction. International Journal of Eating Disorders 35(1): 48-58. 